\title{
Speeding driving behaviour: Age and gender experimental analysis
}

\author{
Teo Sir Hiang ${ }^{1}$ and Gan Leong Ming ${ }^{1}$ \\ ${ }^{1}$ Faculty of Mechanical Engineering, Universiti Malaysia Pahang, 26600 Pekan, Pahang, Malaysia
}

\begin{abstract}
Road safety is a substantial issue worldwide. Speeding contributed to one-third of all the fatal crashes reported from year 2002 to 2011 with young drivers reported to have the highest fatality and injury rates. This paper studied on the speeding driving behavior of 10 teenagers and 10 adults, from both genders. The aim was to investigate the relationship between age and gender with speeding driving behavior. The drivers were required to drive within an enclosed compound by using a test car. Results showed young and male drivers averagely travelled at higher velocity before entering the roundabout and at the same time accelerate to higher velocity upon exiting the roundabout compared to old and female drivers.
\end{abstract}

\section{INTRODUCTION}

In a study carried out by World Health Organisation (WHO) [1] in the year 2013, about 1.24 million people involved in fatal road accidents. This trend however is worsening, from the ninth in 1990 to the third most common cause of death expected by the year 2020 [2] if no action were to be taken. Road accidents studies in Malaysia was reported as the fifth cause of death where most accidents occurred emerged from driver's behaviour [3][4].

Though there are many types of driving behaviour which lead to the high rate of road accidents, studies showed speeding was the contributing factor to one-third of all the fatal crashes reported from year 2002 to 2011 [5]. Teen drivers was reported to have the highest fatality and injury rates [6][7], especially young male drivers who are known to have greater affinity with speed than other drivers [8]. This suggests the necessity to understand the nature of speeding driving behaviours for this particular set of drivers.

In order to identify and understand the differences between these road accident risk potentials and meanwhile reduce the frequency of road accidents instrumented vehicle is widely used [9]. It is a naturalistic data collection equipment in studying driver behaviour and vehicle dynamics analysis, allowing quantitative assessments of driver performance under real driving events. Today's technology advancements and incorporations of sophisticated sensors in the instrumented vehicle have expanded the capabilities of naturalistic observations [10], correlating driver behaviour, vehicle dynamics performance and the road profile conditions [11].

This paper studied on the speeding driving behavior of 20 volunteer drivers, which are 10 teenagers aged from
20 to 25 , with driving experience less than 10 years and 10 adults aged from $35-40$, with at least 15 years of driving experience, from both genders, by utilising a test car. The aim was to investigate the relationship between age and gender with speeding driving behavior. With the equipped sophisticated sensors, the vehicle dynamics performance of the test car shall reveal the driving behavior of the drivers.

\section{EXPERIMENTAL SET UP}

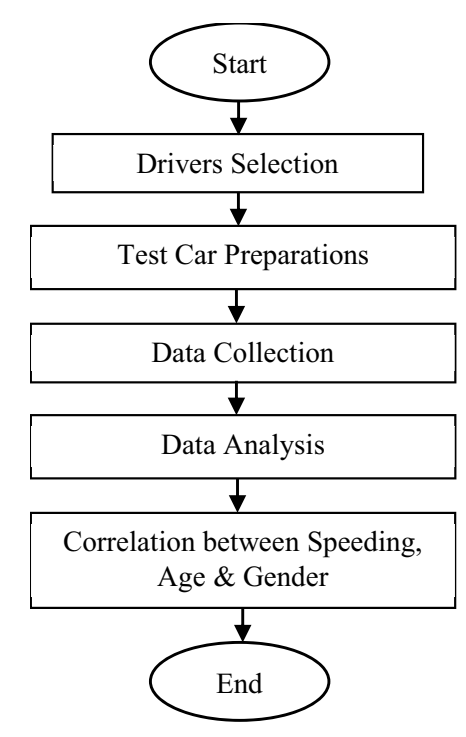

Figure 1. Standard Operating Procedures (SOP).

\subsection{Drivers Selection}

The drivers were selected via convenience sampling. Ten teenagers aged from 20 to 25 and ten adults aged from $35-40$, from both genders. 


\subsection{Test Car Preparations}

Before data collections, the sensors were calibrated and set to ensure proper and accurate data collection. The sensors involved in data collection were tabulated as shown below.

Table 1. Test Car and List of sensors involved.

\begin{tabular}{|c|l|}
\hline Type & \multicolumn{1}{c|}{ Description } \\
\hline Test Car & $\begin{array}{l}\text { The test car is an instrumented } \\
\text { vehicle, equipped with multitude } \\
\text { of sensors for vehicle dynamics and } \\
\text { performance testing. }\end{array}$ \\
\hline $\begin{array}{c}\text { Brake force } \\
\text { sensor }\end{array}$ & $\begin{array}{l}\text { To measure the brake force applied } \\
\text { and displacement of the brake pedal } \\
\text { upon car deceleration. }\end{array}$ \\
\hline Throttle Pedal & $\begin{array}{l}\text { Measures the displacement of the } \\
\text { throttle pedal when the driver } \\
\text { accelerates. }\end{array}$ \\
\hline GPS sensor & $\begin{array}{l}\text { Shows the direction and position of } \\
\text { the test car and meanwhile obtain } \\
\text { the velocity and course travelled. }\end{array}$ \\
\hline
\end{tabular}

\subsection{Data Collection}

The experiments were carried out in the morning under clear blue sky to ensure accurate GPS data collection. In order to minimize biased results due to test car unfamiliarity, the drivers were given the opportunity to drive along the test location for a few laps. Meanwhile, data collection was conducted when there was an absence of other vehicles on the test location when the experiment was carried out. The test location was within an enclosed compound to ensure the convenience of the drivers. The test location is as shown in Figure 2 below.

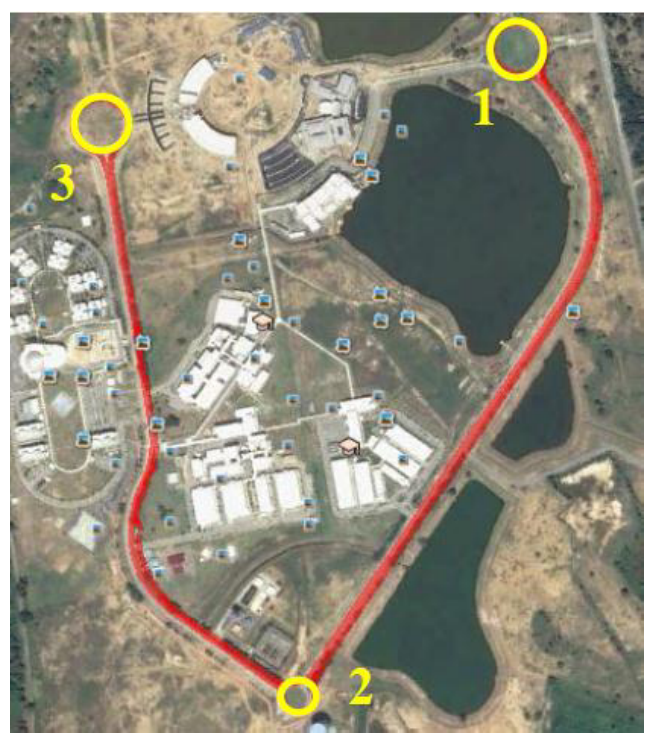

Figure 2. Test location.

\subsection{Data Analysis}

The location which was analysed in this study was further minimized to only around the roundabout 1 as labelled in Figure 3. The roundabout was further divided into 3 sections; section A: before entering roundabout; section B: roundabout; section $\mathrm{C}$ : exiting roundabout. GPS sensor was generally used to analyse on the travelling speed the drivers were in throughout the experiment. The brake force sensor was specifically used to study the brake force applied by the drivers upon reaching the roundabout (Section A) while the throttle pedal displacement sensor was specifically used to analysed the vehicle acceleration upon exiting the roundabout (Section $\mathrm{C}$ ).

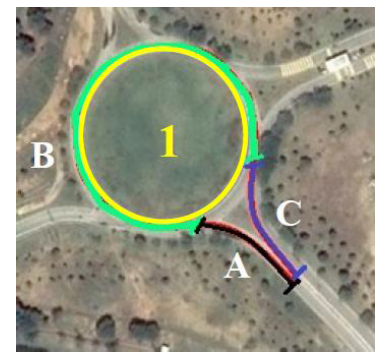

Figure 3. A closer look at roundabout 1.

\subsection{Correlation between Speeding, Age \& Gender}

Travelling at higher speed increases the risk, severity and frequency of road accidents. With the vehicle dynamics results obtained from the test car, the relationship between the four groups of drivers namely male teens, male adults, female teens and female adults with speeding driving behaviour shall be revealed.

\section{RESULTS AND DISCUSSION}

The location which was analysed in this study was further minimized to only around the roundabout 1 as labelled in Figure 3 since the test car showed more obvious fluctuations in terms of vehicle dynamics performance in this section of road compared to the other two roundabouts.

\subsection{Age analysis}

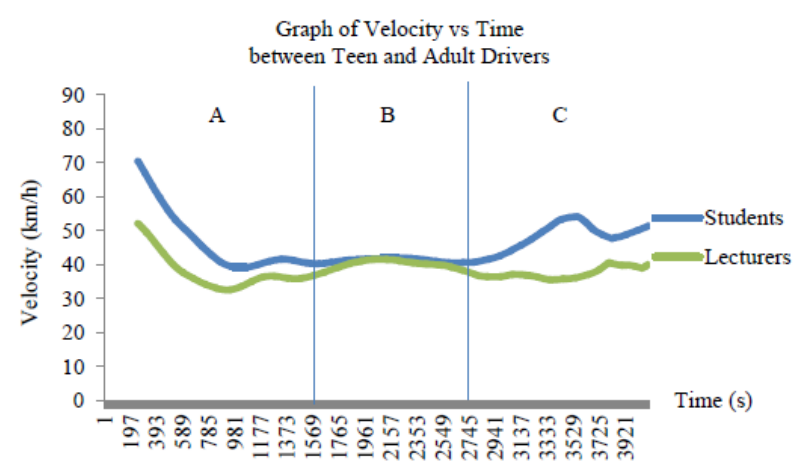

Figure 4. Graph of Velocity vs Time between Teen and Adult Drivers. 


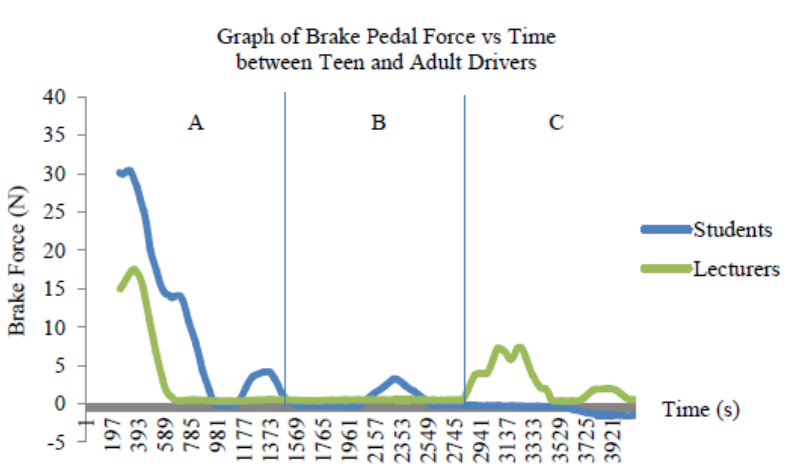

Figure 5. Graph of Brake Force vs Time between Teen and Adult Drivers.

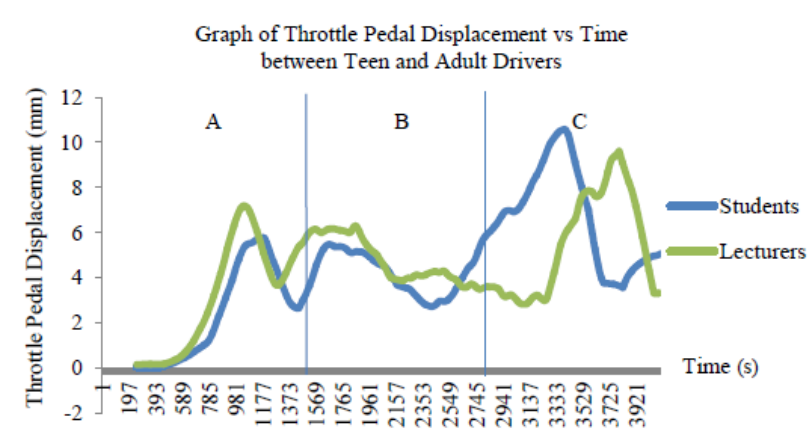

Figure 6. Graph of Throttle Pedal Displacement vs Time between Teen and Adult Drivers.

The age analysis was shown from Figure 4 till 6 . From the roundabout inlet and outlet analysis, it can be seen that younger drivers prefer travelling at higher speed (Figure 4) compared to the older drivers in this study. Upon reaching the inlet of the roundabout, the teens applied higher brake force (Figure 6) where their travelling velocity dropped in a more drastic manner (Figure 4) and upon the exit of roundabout, the teens sped up again as shown by Figure 9. While travelling around the roundabout, which is shown by the middle section of all the graphs from Figure 4 till Figure 6, there was no significant difference among the teens and adults. This suggests that both the teens and adults travel at a considerably same manner.

\subsection{Gender Analysis}

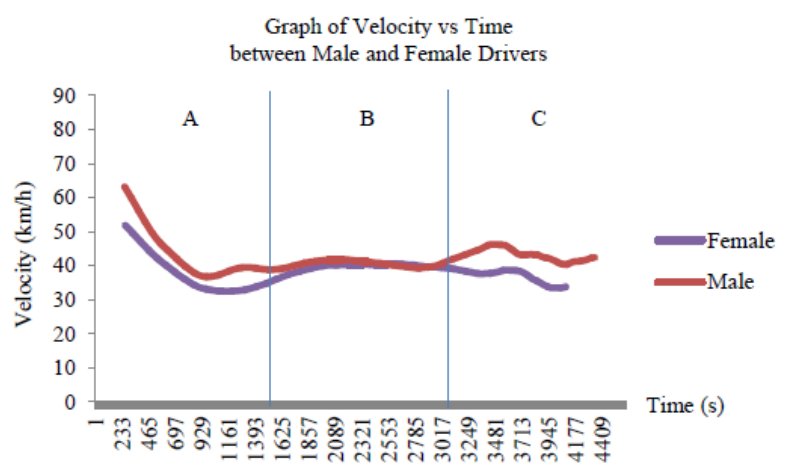

Figure 7. Graph of Velocity vs Time between Male and Female.

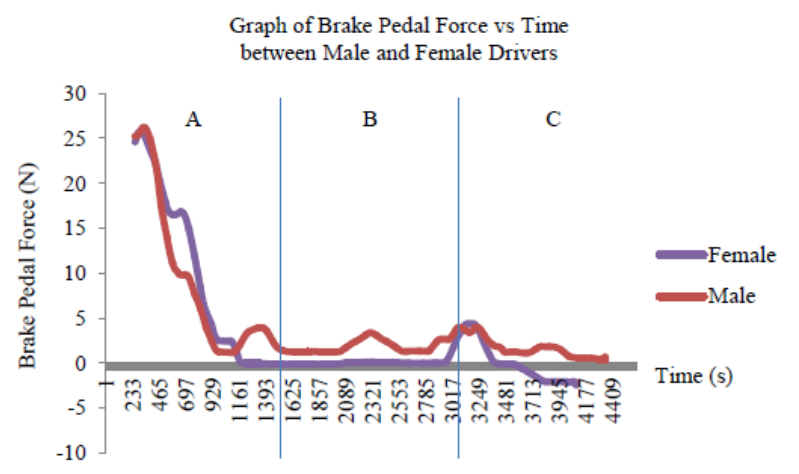

Figure 8. Graph of Brake Pedal Force vs Time between Male and Female.

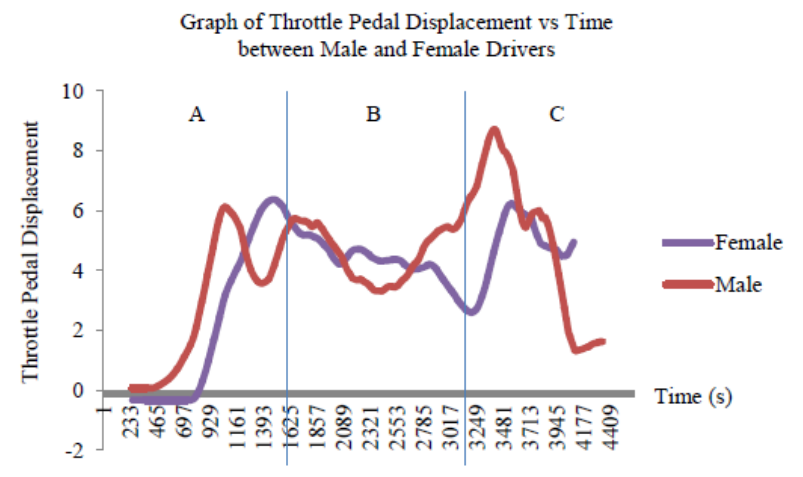

Figure 9. Graph of Throttle Pedal Displacement vs Time between Male and Female.

The gender analysis was shown from Figure 7 till 9. From the roundabout inlet and outlet analysis, it can be seen that male drivers prefer travelling at higher speed (Figure 4) compared to the female drivers. Upon reaching the inlet of the roundabout, even though the female drivers travel at lower speed, they applied a considerable equal amount of brake force as the male drivers. This indicates that the female drivers were more cautious upon entering the roundabout which explains the drop of velocity at the beginning section of Figure 7 . Upon the exit of roundabout, the male drivers sped up faster, which is indicated by the throttle pedal displacement peak in Figure 9. While travelling around the roundabout, which is shown by the middle section of all the graphs from Figure 7 till Figure 9, there was no significant difference among the drivers. This suggests that both the male and female drivers travel at a considerably same manner.

\section{CONCLUSIONS}

Younger drivers practice speeding more often or to a greater extent than the older drivers and young male drivers have greater affinity with speed than other drivers as shown by the results obtained in this study.

\section{FUTURE STUDY}

The future study shall include more drivers and involve more sophisticated sensors in order to further verify the results obtained in this study. The traffic psychology of 
the drivers shall be included to enhance this driving behavior study.

\section{ACKNOWLEDGEMENTS}

The authors would like to be obliged to Universiti Malaysia Pahang for providing laboratory facilities and financial assistance under project no. RDU130130. Meanwhile, I would like to personally thank the drivers and everyone who has directly or indirectly involved in helping me in completing this study.

\section{REFERENCES}

1. WHO $\mid$ Road traffic injuries, http://www.who.int/violence_injury_prevention/roa d_traffic/en/ (2013)

2. S. M. R. Ghadiri, J. Prasetijo, A.F. Sadullah, M. Hoseinpour \& S. Sahranavard, Intelligent speed adaptation: Preliminary results of on-road study in Penang, Malaysia. IATSS Research, 36(2), 106-114. doi: http://dx.doi.org/10.1016/j.iatssr.2012.08.001 (2013)

3. M.R. Othman, Z. Zhong, I. Takashi and M. Tetsuo, A study of analysis method for driver features extraction (2008)

4. N.M. Nor, A. Wahab, N. Kamaruddin and H. Majid, Pre-post accident analysis relates to pre-cursor emotion for driver behavior understanding. Proceedings of the 11th WSEAS international conference on Applied computer science: 152-157 (2011)

5. P. Schroeder, L. Kostyniuk \& M. Mack, 2011 National Survey of Speeding Attitudes and Behaviors. (Report No. DOT HS 811 865). Washington, DC: National Highway Traffic Safety Administration (2013)

6. A. Nayum, The Role of Personality and Attitudes in Predicting Risky Driving Behavior. Master Thesis. University of Oslo, Norway (2008)

7. J.Q. Wang, K.Q. Li and X.Y. Lu, Chapter 5 - Effect of human factors on driver behavior, in advances in intelligent vehicles. 111-157. ISBN 9780123971999, http://dx.doi.org/10.1016/B978-0-12-3971999.00005-7 (2014)

8. C. Ferguson, L. Cohen, J.A. Pooley and A. Guilfoyle, The Theory of Planned Behaviour (TPB) and speeding behaviour of young drivers (2006)

9. A. Sukardi et al, Enhancement of instrumented car design for driver behaviour research. Journal of Asian Scientific Research. 4(7): 314-319. Retrieved from http://www.aessweb.com/pdf-files/jasr(icetsr)2014-4(7)-314-319.pdf (2014)

10. B.E. Porter, Handbook of traffic psychology. Elsevier (2011)

11. M. Rizzo, J. Jermeland and J. Severson, Instrumented Vehicles and Driving Simulators. 1(4): 291-296 (2002) 